\title{
Peptide-Modified Dendrimer Nanoparticles for Targeted Therapy of Colorectal Cancer
}

\author{
Mariana R. Carvalho, Cristiana R. Carvalho, F. Raquel Maia, David Caballero, \\ Subhas C. Kundu, Rui L. Reis, and Joaquim M. Oliveira*
}

Peptides have recently emerged as a promising class of targeting ligands for specific drug delivery in cancer treatment, which avoid undesirable side effects of the systemic administration of chemotherapeutics. Their conjugation with nanoparticles has been demonstrated to improve the functionality of peptides resulting in a versatile platform for biomedical applications. In this work, the development of carboxymethylchitosan/poly(amidoamine) (CMCht/PAMAM) dendrimer nanoparticles functionalized with YIGSR laminin receptor binding peptide for the active targeting and specific delivery of therapeutic agents into colorectal cancer cells is described. The successful functionalization is confirmed by several physico-chemical characterization techniques. The selectivity of the YIGSR-CMCht/PAMAM dendrimer nanoparticles is first validated in vitro using a micropatterned array of $67 \mathrm{kDa}$ laminin receptor. Next, the specificity of YIGSR-CMCht/PAMAM dendrimers nanoparticles toward laminin receptor is further confirmed both in 2D and 3D settings using HCT-116 colorectal cancer cells and L929 fibroblasts in co-culture. Finally, gemcitabine-loaded YIGSR-CMCht/PAMAM dendrimer nanoparticles induce a targeted mortality on HCT-116 cancer cells in a co-culture scenario. Overall, the study shows solid evidence that YIGSR laminin receptor binding peptide coupled to CMCht/PAMAM dendrimer nanoparticles may be employed as an anticancerous target for the specific and intracellular delivery of chemotherapeutic agents.

\section{Introduction}

Cancer is a leading cause of death worldwide, with more than 10 million new cases each year, and an estimation of $\approx 13.1$ million cancer-related deaths by $2030 .^{[1]}$ Typically, cytotoxic chemotherapies have a narrow therapeutic window, with high peaks of plasma concentration. This leads to high-dose requirements with adverse side effects, reduced therapeutic indices, nonspecific targeting, and development of multiple drug resistance. ${ }^{[2]}$

Nanotechnology has evolved as an exciting platform in the field of cancer research with promises to improve the pharmacology of current cancer therapeutics. ${ }^{[3]}$ Drug-loaded nanoparticles (NPs) offer several advantages over free drugs. This includes their capabilities to encapsulate large amounts of chemotherapeutic agents, a prolonged half-life, and an increased targeting efficiency leading to reduced toxicity. ${ }^{[4]}$ Nanoparticle size, core properties, and surface modifications are considered as key factors affecting the clearance rate and organ distribution..$^{[5]}$ A significant number of nanomaterials, including inorganic nanoparticles, liposomes, micelles, and polymers have been developed for targeted drug delivery in cancer. $^{[6]}$ Dendrimers are considered a promising alternative because of their advanced capabilities, which make them ideal tools for targeted drug delivery. As an example, they can increase the solubility and bioavailability of hydrophobic drugs. ${ }^{[7]}$ Further, their architecture and availability of active functional groups allow the easy addition of moieties and the encapsulation of drugs. ${ }^{[7]}$
M. R. Carvalho, C. R. Carvalho, Dr. F. R. Maia, Dr. D. Caballero, Prof. S. C. Kundu, Prof. R. L. Reis, Dr. J. M. Oliveira

3B's Research Group, I3Bs - Research Institute on Biomaterials Biodegradables and Biomimetics

University of Minho

Headquarters of the European Institute of Excellence on Tissue Engineering and Regenerative Medicine

AvePark, Parque de Ciência e Tecnologia, Zona Industrial da Gandra 4805-017 Barco, Guimarães, Portugal

E-mail: miguel.oliveira@i3bs.uminho.pt
M. R. Carvalho, C. R. Carvalho, Dr. F. R. Maia, Dr. D. Caballero, Prof. S. C. Kundu, Prof. R. L. Reis, Dr. J. M. Oliveira ICVS/3B's - PT Government Associate Laboratory Braga/Guimarães, Portugal

M. R. Carvalho, C. R. Carvalho, Dr. F. R. Maia, Prof. R. L. Reis, Dr. J. M. Oliveira

The Discoveries Centre for Regenerative and Precision Medicine Headquarters at University of Minho

Avepark 4805-017 Barco, Guimarães, Portugal 
Different types of active tumor-targeted ligands, such as RGD peptide, folic acid, and transferrin, have been employed in conjunction with NPs to specifically direct and enhance drug accumulation in the tumor. ${ }^{[8]}$ In particular, doxorubicinloaded HPMA-copolymer conjugated with GE11 oligopeptide have been employed to specifically target colorectal cancer (CRC) cells with EGFR overexpression. A high cellular uptake of the doxorubicin-loaded NP was observed, achieving a selective release of the drug. ${ }^{[9]}$ Similarly, a multifunctional nanosystem based on methotrexate-loaded guar gum NPs functionalized with folic acid (MTXFA-GGNP) has been employed to release methotrexate at colonic $\mathrm{pH}$ values (6.8) in CRC. Interestingly, the engineered NPs displayed preferential in vivo uptake in colon tissue. ${ }^{[10]}$ However, most of these approaches were mainly studied in 2D environments. In addition, these studies also lacked a visual representation and analysis of NPs internalization in a coculture scenario, and importantly, their validation using nativelike $3 \mathrm{D}$ settings.

Despite all the efforts invested in the development of targeted drug delivery systems for improved cancer therapeutics, their performance is still limited for medical applications. New approaches are needed to target efficiently and precisely the cancer cells. In this regard, the YIGSR laminin receptor binding peptide has demonstrated to be a promising class of targeting ligand for specific drug delivery in cancer treatment. Cancer cells from various sources express high levels of the $67 \mathrm{kDa}$ laminin receptor (67LR), ${ }^{[11]}$ including bile duct carcinoma, colorectal carcinoma, cervical cancer, and breast carcinoma, ${ }^{[12]}$ which are shown to be correlated with tumor invasiveness. ${ }^{[13]}$ Earlier work has demonstrated that the laminin binding capacity of plasma membranes isolated from human invasive breast carcinomas is 50 -fold greater than that of membranes from benign lesions or normal tissue. ${ }^{[14]}$

In this study, we hypothesize that the peptide sequence YIGSR grafted onto carboxymethylchitosan/poly(amidoamine) (CMCht/PAMAM) dendrimer NPs promotes specific and targeted internalization into CRC cells. ${ }^{[15]}$ To this end, we first characterize the morphology and successful functionalization of CMCht/PAMAM and YIGSR-modified CMCht/PAMAM dendrimer NPs by AFM, TEM, DLS, and $\mathrm{H}^{1} \mathrm{NMR}$. The selectivity of the YIGSR-CMCht/PAMAM dendrimer nanoparticles was first validated in vitro using a micropatterned array of $67 \mathrm{kDa}$ laminin receptor. Next, we investigate the effect of both types of dendrimer NPs on the viability of HCT-116 CRC cells or L929 fibroblasts. Next, the targeted internalization of the NPs is assessed in a co-culture of HCT-116 CRC cells and L929 fibroblasts both in traditional well plates (2D) or encapsulated within a 3D Matrigel matrix.

\section{Results and Discussion}

\subsection{Physico-Chemical Characterization of Dendrimer Nanoparticles}

We first investigated the attachment of the YIGSR peptide on the dendrimer NPs surface via carbodiimide chemistry (Figure 1A), and the morphology and size of both type of NPs. STEM images revealed a monodisperse round-shaped morphology (Figure 1B), which was confirmed by AFM measurements (see Figure S1A, Supporting Information). These results suggested the successful grafting of the peptide sequence, which conferred the YIGSR-CMCht/PAMAM dendrimer NPs a larger size. DLS was used to quantify the size of the NPs. Figure 1C shows the peaks associated with both the CMCht/PAMAM and YIGSR-CMCht/PAMAM dendrimer NPs. In the former, two main peaks were obtained, which corresponded to individual and aggregated NPs. The first peak provided the average size of the individual NPs as $54 \pm 7 \mathrm{~nm}$, whereas the second one corresponded to NP aggregates with a much bigger size. In contrast, YIGSR-CMCht/PAMAM dendrimer NPs displayed three peaks. The first peak located around $6 \mathrm{~nm}$ corresponded to unreacted PAMAM G1.5. The reason is that the first step in the synthesis of the dendrimer NPs is increasing the generation of the PAMAM-CT (G 1.5), which has a theoretical size equal to the one provided by the peak, and therefore, this peak was assumed to correspond to unreacted G1.5. The second peak located around $130 \pm 20 \mathrm{~nm}$ corresponds to the YIGSR-modified dendrimer NPs. Finally, the last peak is associated with aggregated NPs. Altogether, these results show that attachment of the peptide significantly increased the size of the NPs by $\approx 2.5$-fold without affecting the NPs polydispersity index (PDI) with values of 0.29 and 0.37 for CMCht/PAMAM and YIGSR-CMCht/PAMAM PDI, respectively.

Figure 1D shows the FTIR spectrum of the CMCht/PAMAM and the newly modified YIGSR-CMCht/PAMAM dendrimer NPs. The spectrum of the modified NPs shows an increase in peak intensity at $1700 \mathrm{~cm}^{-1}$ attributed to the amide II and $\mathrm{C}-\mathrm{N}$ stretching vibrations. ${ }^{[16]}$ This is an evidence of the presence of amine groups as well as of the chemical bonding between the CMCht/PAMAM and the peptide. Similarly, the $520 \mathrm{~cm}^{-1}$ free amino acid peak and the $1120 \mathrm{~cm}^{-1} \mathrm{NH}_{3}$ vibration appear after NP modification. ${ }^{[11,17]}$ Moreover, both NPs showed characteristic peaks, such as the strong and broad peak of absorption at $\approx 3400 \mathrm{~cm}^{-1}$, which are assigned to the stretching vibration of the structural $\mathrm{N}-\mathrm{H}$ overlapping the $\mathrm{O}-\mathrm{H}$ stretching. Similarly, the attachment of the YIGSR peptide was further confirmed by the analysis of the chemical signature obtained by $\mathrm{H}^{1} \mathrm{NMR}$ (Figure 1E). ${ }^{[18]}$ Bearing in mind the analysis of $\mathrm{H}^{1} \mathrm{NMR}$ spectra (see Figure S2, Supporting Information), we can state that the signature protons of $\mathrm{CH}_{2}$ and $\mathrm{CH}_{3}$ of the YIGSR peptide are present in the YIGSR-CMCht/PAMAM around 2 and $3 \mathrm{ppm}$, indicating the successful grafting of the peptide. Moreover, the broad singlet at $3.02 \mathrm{ppm}$ of the CMCht/PAMAM is also present in the modified nanoparticles. Taken together, the results obtained indicate that the peptide was successfully conjugated to the NPs.

We next measured the Zeta potential values of both unmodified CMCht/PAMAM and YIGSR-modified CMCht/PAMAM dendrimer NPs. Figure $1 \mathrm{~F}$ shows that the formers have a value of $-14.7 \pm 3.0 \mathrm{mV}$ in PBS and $-34.3 \pm 3.0 \mathrm{mV}$ in $\mathrm{dd}_{2} 0$. In contrast, YIGSR-modified CMCht/PAMAM dendrimer NPs have a value of $-9.3 \pm 0.8 \mathrm{mV}$ in PBS and $-19.3 \pm 0.8 \mathrm{mV}$ in $\mathrm{ddH}_{2} 0$. The difference between YIGSR-modified dendrimer NPs (less negative) and unmodified NPs (more negative), indicates a reduction in the number of carboxylic acid groups on the NPs surface following peptide binding. Moreover, the addition of the positively charged arginine present in the peptide sequence suggests a successful grafting. It is expected that $\mathrm{CMCht}$ has a good $\mathrm{pH}$ and ion sensitivity in aqueous solution due to abundant $-\mathrm{COOH}$ and $-\mathrm{NH}_{2}$ 
A)
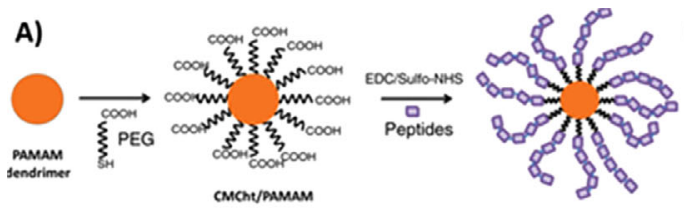

ness.conche/mamam

D)

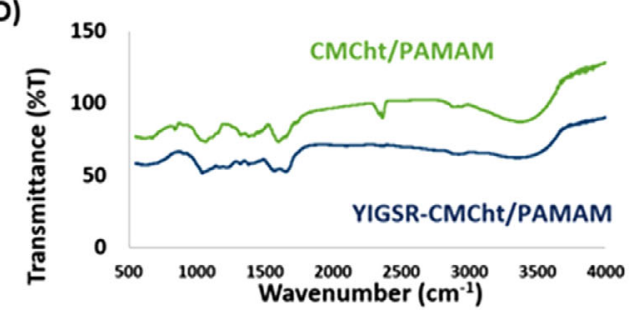

B)
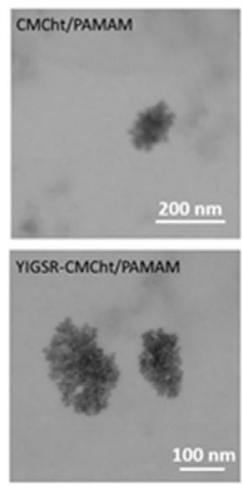

$100 \mathrm{~nm}$
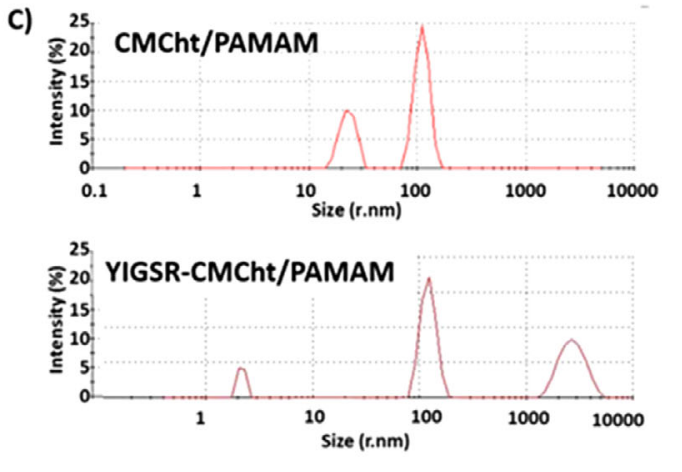

E)



F)

\begin{tabular}{cccc}
\hline Sample & \multicolumn{2}{c}{$\begin{array}{c}\text { Zeta Potential } \\
(\mathrm{mV})\end{array}$} & $\begin{array}{c}\text { Particle } \\
\text { diameter } \\
(\mathrm{nm})\end{array}$ \\
\hline & $P B S 7.4$ & $d d \mathrm{H}_{2} \mathrm{O}$ & $P B S$ \\
\cline { 2 - 4 } CMCht/ & $-14.7 \pm 3$ & $-34.3 \pm 3$ & $54 \pm 7$ \\
PAMAM & & & \\
\hline YIGSR- & $-9.31 \pm$ & $-19.33 \pm$ & $130 \pm$ \\
$\begin{array}{c}\text { CMCht/PA } \\
\text { MAM }\end{array}$ & 0.82 & 0.80 & 19.7 \\
\hline
\end{tabular}

G)

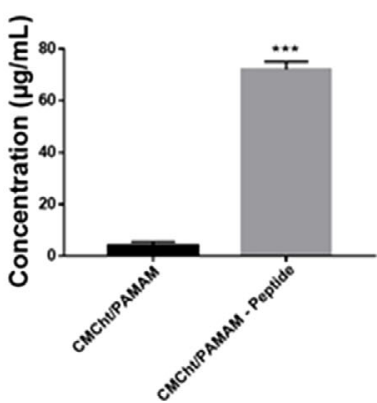

Figure 1. Physico-chemical characterization of dendrimer nanoparticles. A) Schematic representation of the dendrimer NPs modification with YICSR peptide from laminin via carbodiimide chemistry. B) STEM image of CMCht/PAMAM and YICSR-CMCht/PAMAM dendrimer NPs. C) Representative graphic of the particle size distribution of CMCht/PAMAM and YICSR-CMCht/PAMAM NPs, showing that the peptide sequence conferred the NPs a larger size. D) FTIR analysis of CMCht/PAMAM and YIGSR-CMCht/PAMAM dendrimer NPs, showing an increase in intensity of the bands at 1700 $\mathrm{cm}^{-1}$ for YIGSR-CMCht/PAMAM dendrimers. E) $\mathrm{H}^{1}$ NMR spectra of YIGSR-CMCht/PAMAM, CMCht/PAMAM, and YIGSR. The YIGSR-CMCht/PAMAM shows a peak at $3 \mathrm{ppm}$ and no peak at $4.3 \mathrm{ppm}$ suggesting that the substitutions occurred mainly on the C2 amino group of CMCht. F) Table of the mean NP diameter and Zeta potential in PBS and $\mathrm{dd}_{2} \mathrm{O}$, showing an increase in diameter and a decrease in Zeta potential upon the addition of YICSR. G) Determination of peptide concentration by protein quantification (BCA protein quantification) in CMCht/PAMAM and YICSR-CMCht/PAMAM.

groups. On the other hand, since the Zeta potential of NPs is determined by their surface properties, this data shows the negatively charged carboxymethyl groups in the CMCht/PAMAM dendrimer NPs. The different Zeta potential values obtained in $\mathrm{ddH}_{2} \mathrm{O}$ and PBS can be explained by the fact that the CMCht behaves as a weak polyanionic polyelectrolyte at physiological $\mathrm{pH}$, that is, the amino groups are not protonated and most of carboxyl groups are not dissociated.

Further characterization was achieved by quantifying the amount of coupled peptide using the BCA protein quantification assay and compared to a standard curve using BSA (Figure 1G). Results show a significant difference between the levels of protein on non-modified and YIGSR-grafted CMCht/PAMAM dendrimer NPs. The former shows an amount of $3.60 \pm 1.62 \mu \mathrm{g} \mathrm{mL}^{-1}$, whereas the later has a concentration of $71.00 \pm 3.75 \mu \mathrm{g} \mathrm{mL}^{-1}$. This indicates that the peptide sequence YIGSR is successfully attached to the dendrimer NPs. Finally, the presence of the peptide on the CMCht/PAMAM dendrimer NPs was investigated by UV spectroscopy (Figure S1B, Supporting Information). The peptide sequence YIGSR incorporates the amino acid tyrosine, which exhibits two characteristic absorbance peaks in the UV spectral region at $\approx 230 \mathrm{~nm}$ and $280 \mathrm{~nm} .{ }^{[19]}$ The UV spectra were obtained using CMCht/PAMAM and modified YIGSR-CMCht/PAMAM dendrimer NPs for comparison. Two peaks located around $275 \mathrm{~nm}$ were observed. This indicated that the peptide is effectively grafted to the polymer backbone.

\subsection{Targeted Detection of FITC-YIGSR-CMCht/PAMAM on a Micropatterned Laminin Receptor Array}

The $67 \mathrm{kDa}$ high affinity LR is a non-integrin cell surface receptor of the extracellular matrix. The expression of this receptor is thought to be increased in neoplastic cells, which directly correlates with an enhanced invasiveness and metastatic potential. ${ }^{[20]}$ To confirm this higher expression, we first performed an immunocytochemistry analysis to assess qualitatively the differences in LR expression in HCT-116 and L929 cells at $24 \mathrm{~h}$ and $72 \mathrm{~h}$. HCT-116 cells displayed round morphologies and proliferated forming dense aggregates (Figure 2A). In contrary, L929 fibroblasts showed highly spread phenotypes. Importantly, HCT116 displayed a large LR signal both at $24 \mathrm{~h}$ and $72 \mathrm{~h}$. This is in contrast to L929 fibroblasts, which showed a low LR expression. Taken together, these results suggest that the $67 \mathrm{kDa}$ LR may be employed as a cancer-specific target to specifically deliver drugloaded YIGSR-CMCht/PAMAM dendrimer NPs in a precise and efficient manner.

Next, we evaluated in vitro the specificity of the YIGSRCMCht/PAMAM dendrimer NPs toward the LR. For this, an array of $67 \mathrm{kDa}$ LR was micropatterned on a functionalized glass coverslip by micro-contact printing to recreate in vitro the physiological target (Figure 2B). Next, FITC-labeled YIGSRCMCht/PAMAM dendrimer NPs were incubated on top of the LR array. We observed that the FITC-labeled NPs attached mainly 

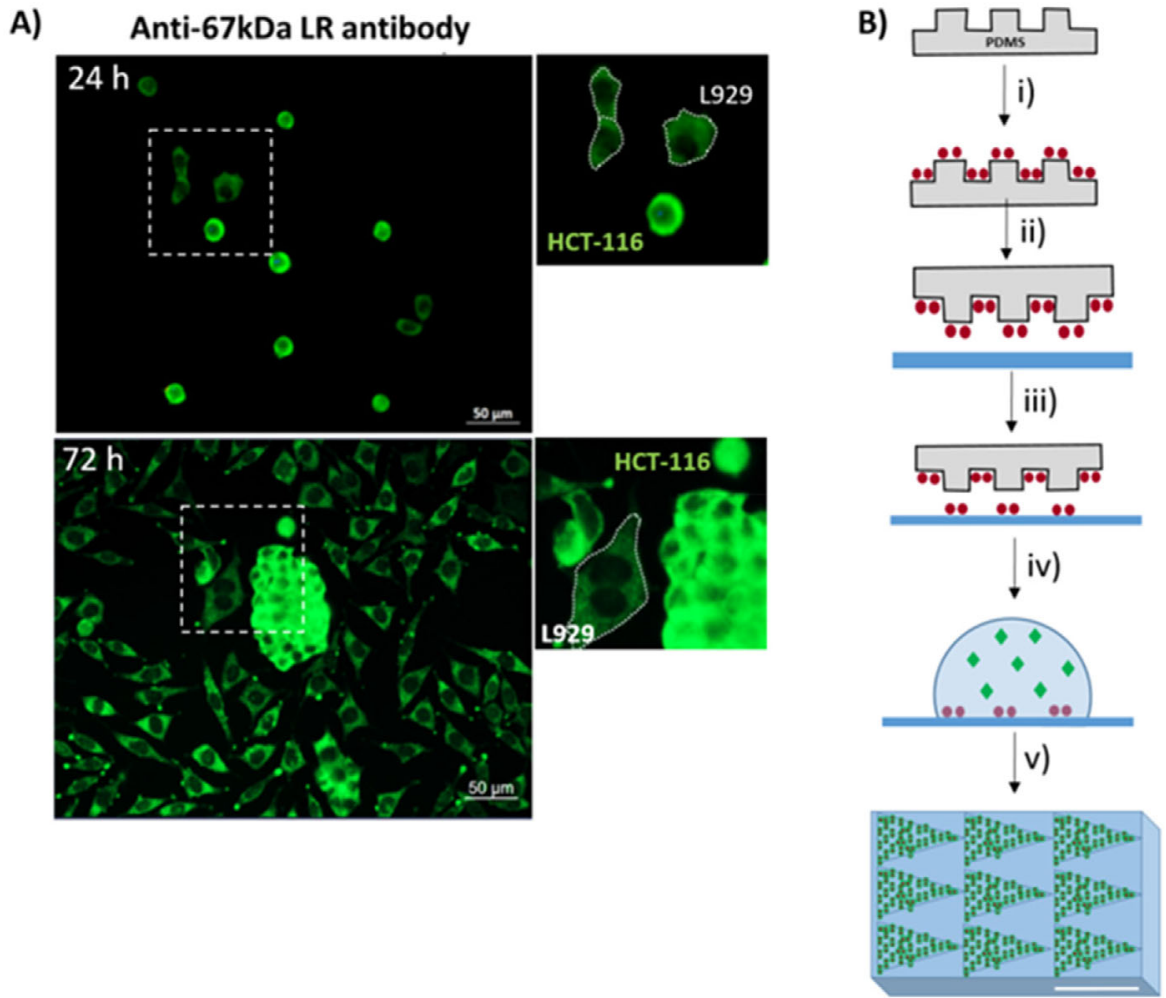

LR protein
FITC-YIGSR-CMCht/PAMAM
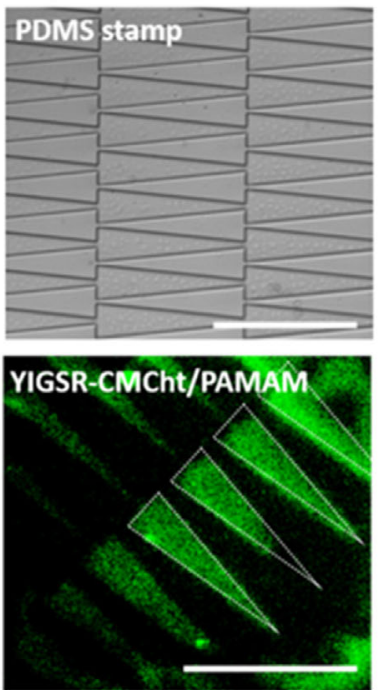

Figure 2. Specificity of FITC-YIGSR-CMCht/PAMAM dendrimer NPs on a micropatterned LR array. A) Immunocytochemistry of anti-67 kDa LR (green) performed on a co-culture of HCT-116 CRC cells and L929 fibroblasts (stained in red; see Figure S3, Supporting Information) cells at 24 and 72 h. An overexpression of LR on HCT-116 is visible at both time points. B) (Left) Schematic representation of the steps involved in the microcontact printing of the LR: i) incubation of the PDMS stamp with the LR solution; ii) microcontact printing of the LR on top of a functionalized (APTES $5 \%$ and glutaraldehyde) glass coverslip; iii) PDMS stamp removal and rinsing with $\mathrm{ddH}_{2} \mathrm{O}$; iv) incubation with FITC-YICSR-CMCht/PAMAM; and v) rinse with dd $\mathrm{H}_{2} \mathrm{O}$ to remove the excess of FITC-YICSR-CMCht/PAMAM. (Right) Representative brightfield and fluorescence microscopy images of the PDMS stamp and FITC-YICSRCMCht/PAMAM NPs array displaying the triangular micro-sized LR features. Scale bar: $100 \mu \mathrm{m}$.

on top of the triangular micropatterned regions, which contained the $67 \mathrm{kDa}$ LR protein. Overall, these results show a strong affinity of between the NPs grafted with a portion of YIGSR peptide and the LR protein. However, more complex experiments involving protein receptors other than LR may need to be also tested to univocally prove a really specific affinity for this receptor.

\subsection{Cytotoxicity Tests: Metabolic Activity and Cell Proliferation}

The cytotoxicity of the dendrimer NPs was assessed by measuring cell metabolic activities and proliferations by means of Alamar blue and DNA quantification assays. HCT-116 cancer cells and L929 fibroblasts were exposed to CMCht/PAMAM, YIGSRCMCht/PAMAM, and GEM-YIGSR-CMCht/PAMAM at a final concentration of $0.5 \mathrm{mg} \mathrm{mL}^{-1}$ over a period of $72 \mathrm{~h}$. This value was selected taking into consideration the maximum concentration of pure dendrimer NPs (i.e., non-modified) that may be employed without observing any cytotoxic effect. ${ }^{[15]}$ It is important to notice that both the metabolic activity and cell viability were assessed in monoculture to discard the possibility of inherent toxicities of non-modified and modified dendrimer NPs. Both HCT-116 cancer cells and L929 fibroblasts significantly proliferated from day 1 to day 3 in the absence (control) and presence of CMCht/PAMAM and YIGSR-CMCht/PAMAM NPs (Figure 3). The obtained results showed no deleterious effects of the non-modified CMCht/PAMAM and the YIGSRCMCht/PAMAM dendrimer NPs on cell viability and proliferation in both cell types. This indicates that the grafting of the YIGSR sequence did not significantly affect cellular behavior.

Conversely, GEM-loaded YIGSR-CMCht/PAMAM NPs had a clear cytotoxicity in both cell types due to the release of the drug, as demonstrated by the decrease in the metabolic activity and DNA amount (Figure 3A,B). Interestingly, this effect was mostly observed at early time points in HCT-116 cancer cells in contrast to L929 fibroblasts, where the cytotoxicity was only observed at $72 \mathrm{~h}$. This suggests that the drug was internalized faster in HCT116 cancer cells due to LR overexpression. For L929 fibroblasts, viability was most likely affected by the release of GEM from the NPs. Regarding the release of GEM from the NPs, and its potential in vivo side effects, it is plausible that the NPs release some amount of drug in the medium before it is internalized by the cells. However, its effect should not be significant because the same conditions and time points were tested in co-culture (similar to in vivo scenario) with an increased cell death for HCT116 cancer cells. Overall, we do not anticipate any significant adverse effect of the released drug, within the range of the used concentrations, on noncancerous cells when eventually used in 
A)

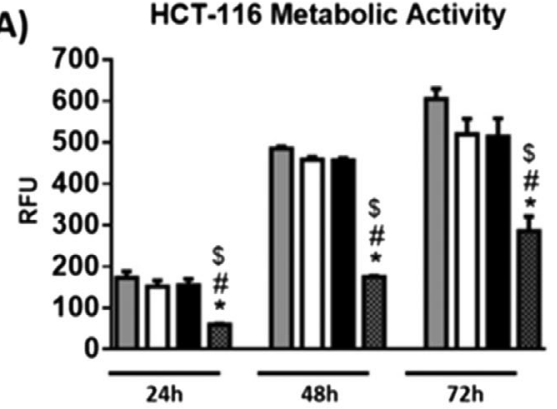

B)

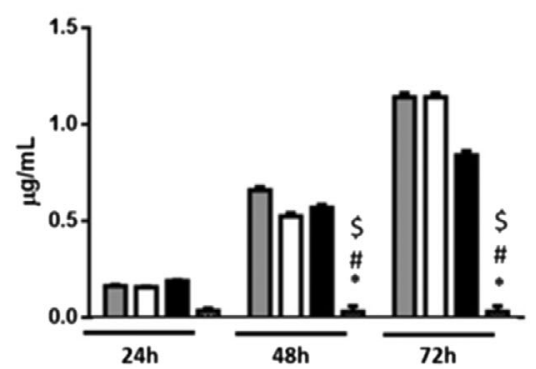

L929 Metabolic activity



DNA Quantification L929

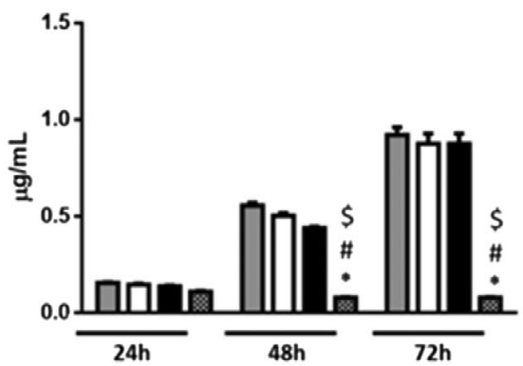

$\square$ Control

$\square$ CMCht/PAMAM

YIGSR-CMCht/PAMAM

GEM-YIGSR-CMCht/PAMAM

Figure 3. Cytotoxicity studies. A) Metabolic activity determined by Alamar blue, and B) DNA quantification results of HCT-116 cancer cells and L929 fibroblasts in the presence of $0.5 \mathrm{mg} \mathrm{mL}^{-1}$ of CMCht/PAMAM, YICSR-CMCht/PAMAM, and GEM-loaded YIGSR-CMCht/PAMAM, at 24, 48, and 72 h. "Significant differences when comparing the different conditions with control $\left(0 \mathrm{mg} \mathrm{mL}^{-1}\right)$ at each time point. \# Significant differences were observed when comparing to CMCht/PAMAM at each time point. \$Significant differences were observed when comparing to YIGSR-CMCht/PAMAM at each time point. $p<0.05$.

vivo. Moreover, it is worth noticing that these effects were observed when HCT-116 and L929 were cultured in separate, and not in co-culture. Only after assessing the noncytotoxic effects of the peptide modification in monoculture, its effect in co-culture was investigated. Overall, these results indicate that GEM-loaded YIGSR-CMCht/PAMAM NPs affected the viability and proliferation of HCT-116 cancer cells and L929 fibroblasts in contrast to non-modified and peptide-grafted dendrimer NPs, but in different time scales.

\subsection{Targeted Internalization of Dendrimer Nanoparticles in 2D and 3D}

We next investigated whether the attachment of YIGSR on the surface of the dendrimer NPs influenced their preferential uptake by HCT-116 cancer cells, which overexpress $67 \mathrm{kDa}$ LR at their surface, in a co-culture with L929 fibroblasts (see Figure 4A). Nanoparticle internalization was first investigated in 2D. As expected, FITC-CMCht/PAMAM NPs widely internalized in both cell types at $24 \mathrm{~h}$ and $72 \mathrm{~h}$, and localized in the cytoplasm and around the nucleus ${ }^{[15,18]}$ (Figure 4B) mainly. In contrast, the peptide-modified YIGSR-CMCht/PAMAM dendrimer NPs internalized preferentially into HCT-116 cancer cells (red) at $24 \mathrm{~h}$ when seeded in a co-culture with L929 fibroblasts (blue). Importantly, a qualitative increase in the number of internalized NPs could be observed from $24 \mathrm{~h}$ to $72 \mathrm{~h}$. This suggested that peptide-grafted NPs were specifically targeted toward HCT-116 cells overexpressing $67 \mathrm{kDa}$ LR.
We next used an in-vivo-like 3D scenario to determine the efficiency of the cellular uptake mediated by the targeted interaction of the YIGSR peptide with the LR. For this, we encapsulated HCT-116 cancer cells and L929 fibroblasts into a 3D matrix of Matrigel. Figure 4B (bottom) shows the cells cultured in the absence (control) and presence of CMCht/PAMAM and YIGSRCMCht/PAMAM dendrimer NPs. We first investigated whether the NPs were capable to diffuse across the meshes of the hydrogel and target the HCT-116 cells. After $24 \mathrm{~h}$, no significant internalization of both CMCht/PAMAM and YIGSR-CMCht/PAMAM NPs was observed (data not shown). Instead, the NPs aggregated in the outer membrane of the cells (see Figure S1E, Supporting Information). This phenomenon may be a consequence of NPs diffusing through the dense mesh of the crosslinked hydrogel, and therefore, taking longer than in 2D to interact with cells and internalize. In contrast, after $72 \mathrm{~h}$, FITC-labeled NPs spread all across the 3D hydrogel accumulating both inside and around the HCT-116 cells. Notably, it was found that YIGSRCMCht/PAMAM NPs internalized preferentially into the HCT116 cancer cells (Figure 4B(1), white arrowheads). In contrast, L929 fibroblasts did not show any significant evidence of NPs internalization (see Figure 4B(2)). These results highlight the differences between 2D and 3D scenarios in drug delivery applications, even in terms of simple biological processes such as the internalization of NPs.

We next quantified the amount of NPs that were internalized in both conditions (2D vs 3D). To this end, flow cytometry analysis was performed using the same experimental conditions. HCT-116 cancer cells were stained with an anti-CD44 
A)

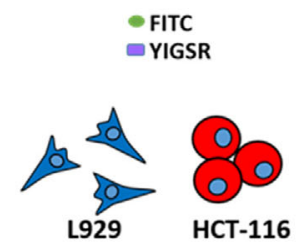

B)

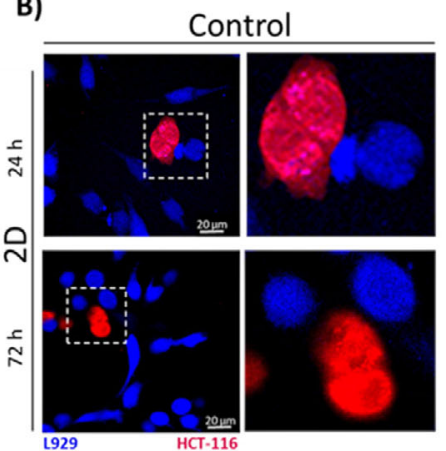

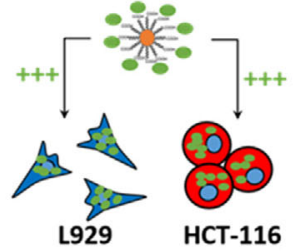

CMCht/PAMAM
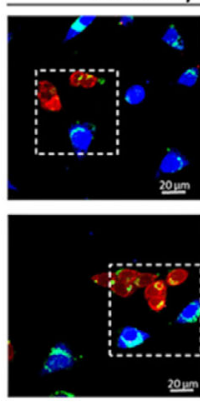

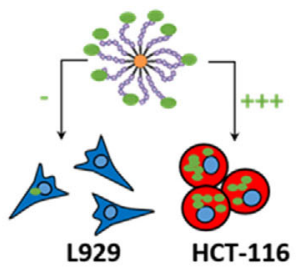

YIGSR-CMCht/PAMAM

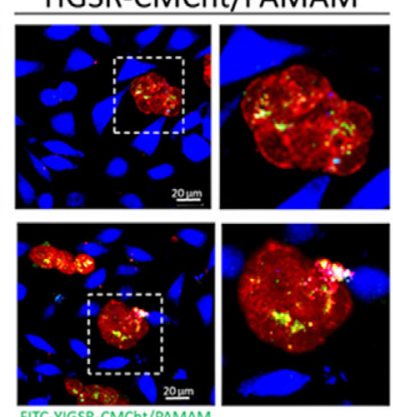

FITC-YIGSR-CMCht/PAMAM

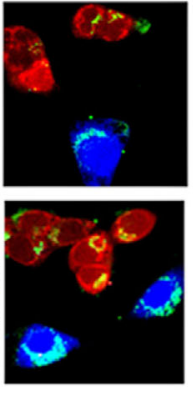

YIGSR-CMCht/PAMAM

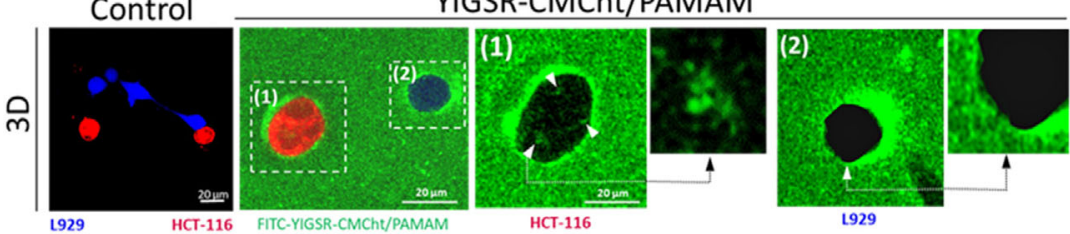

c)
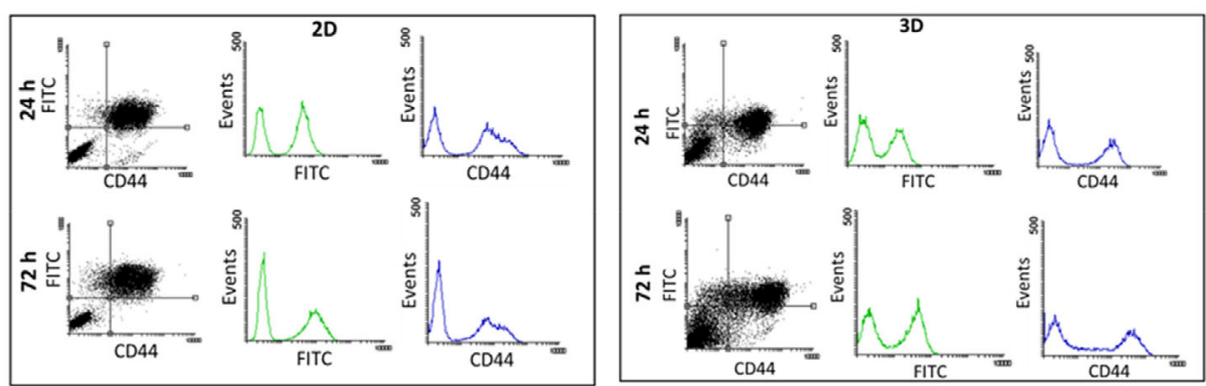

\begin{tabular}{ccccc}
\hline Culture condition & \multicolumn{2}{c}{ 2D } & \multicolumn{2}{c}{ 3D } \\
\hline Cell type & $24 \mathrm{~h}$ & $\mathbf{2 2} \mathrm{h}$ & $\mathbf{2 4 h}$ & $\mathbf{2 2} \mathbf{h}$ \\
\hline HCT-116 & $96.27 \%$ & $98.45 \%$ & $65.52 \%$ & $85.44 \%$ \\
L929 & $2.97 \%$ & $6.56 \%$ & $3.54 \%$ & $9.95 \%$ \\
\hline
\end{tabular}

Figure 4. Internalization of dendrimer nanoparticles. A) Schematics of the different conditions studied. B) Confocal microscopy images of HCT-116 cancer cells (red) and L929 fibroblasts (blue) co-culture in the presence of YICSR-CMCht/PAMAM and CMCht/PAMAM dendrimer NPs in (top) 2D for 24 and $72 \mathrm{~h}$, and (bottom) in 3D for $72 \mathrm{~h}$. In the latter, (1) and (2) show a higher magnification of HCT-116 and L929 cells, respectively, showing the internalization of YICSR-CMCht/PAMAM dendrimer NPs exclusively for HCT-116 (observed only with the $488 \mathrm{~nm}$ filter). Inset images show a more detailed view of the NPs (indicated by white arrowheads). C) Flow cytometry results of NPs internalization in co-culture in both 2D and 3D for 24 and 72 h. Scale bars: $20 \mu \mathrm{m}$.

antibody-PE (see Figure S1C, Supporting Information). In this case, only the HCT-116 cells were stained, serving as a differential marker. The obtained results were in agreement with the fluorescence microscopy results. In 2D, a maximum internalization of NPs (96.27\%) for the HCT-116 cells was observed at $24 \mathrm{~h}$, compared to the low internalization (2.97\%) in L929 fibroblasts (Figure 4C, left). At $72 \mathrm{~h}$, the internalization of NPs increased slightly (98.45\% for HCT-116 cancer cells and 6.56\% for L929 fibroblasts). This clearly showed the lower levels of internalization in L929 fibroblasts when compared to those of HCT-116 cancer cells. In contrast, in 3D scenario, we found that the overall levels of internalization were not as high as in 2D (Figure 4C, right). After $24 \mathrm{~h}$, the level of internalization of targeted NPs in HCT116 cancer cells and L929 fibroblasts was $65.52 \%$ and $3.54 \%$, 
A)
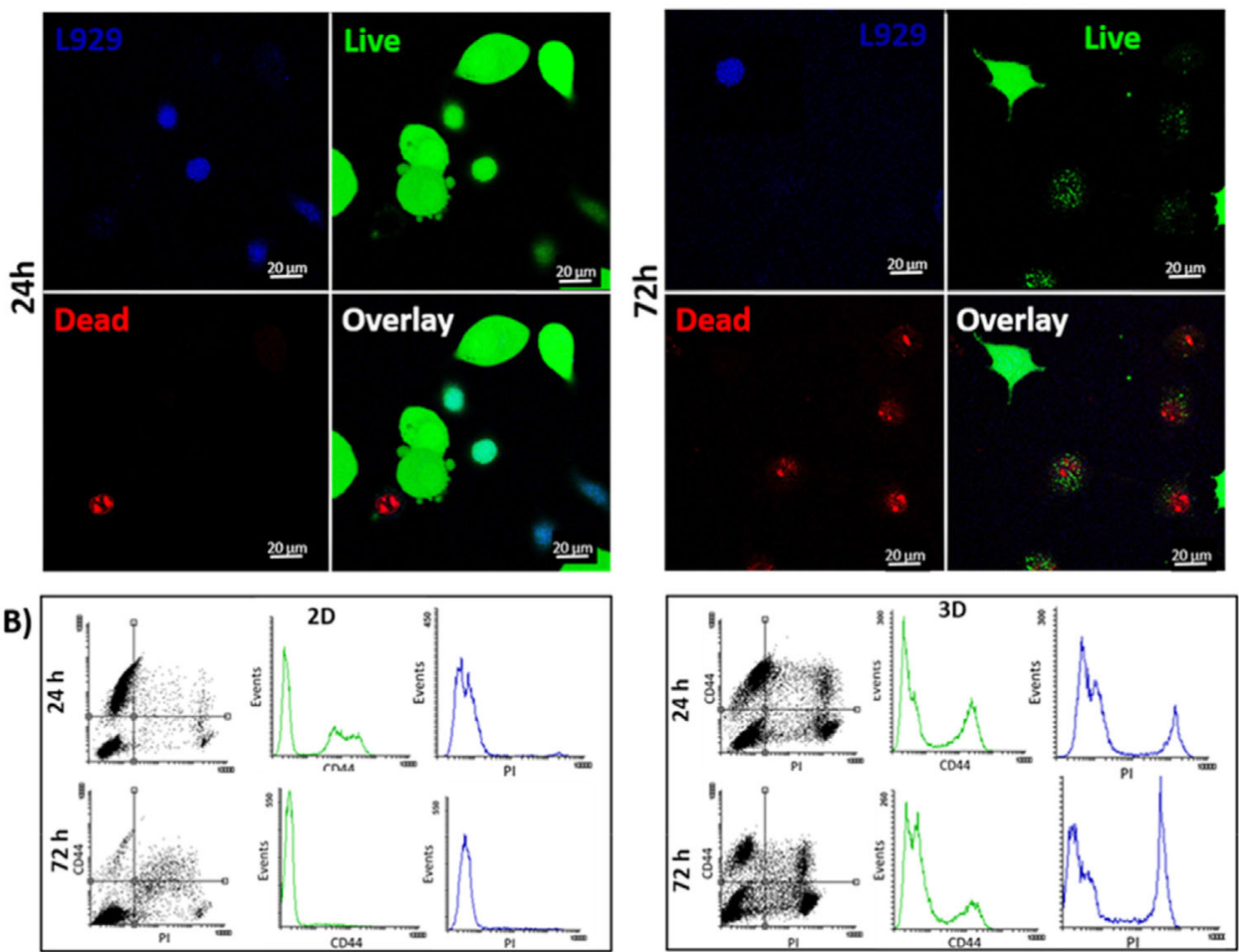

\begin{tabular}{ccccc}
\hline Culture condition & \multicolumn{2}{c}{ 2D } & \multicolumn{2}{c}{ 3D } \\
\hline Cell type & $\mathbf{2 4} \mathbf{h}$ & $\mathbf{7 2} \mathbf{h}$ & $\mathbf{2 4} \mathbf{h}$ & $\mathbf{7 2} \mathbf{h}$ \\
\hline HCT-116 & $4.70 \%$ & $68.72 \%$ & $30.16 \%$ & $31.15 \%$ \\
L929 & $3.44 \%$ & $3.20 \%$ & $26.07 \%$ & $19.52 \%$
\end{tabular}

Figure 5. Cell viability of HCT-116 cancer cells and L929 fibroblasts in the presence of GEM-YIGSR-CMCht/PAMAM dendrimers. A) Live/dead assay performed on a co-culture of HCT-116 cancer cells (unstained) and L929 fibroblasts (in blue) at 24 and $72 \mathrm{~h}$ in 2D. B) Flow cytometry analysis of cell viability in the presence of GEM-YICSR-CMCht/PAMAM in a co-culture of HCT-116 (CD44 positive) and L929 cells (CD44 negative cells).

respectively. At $72 \mathrm{~h}$, these values increased up to $85.44 \%$ and $9.95 \%$, respectively. As mentioned previously, these differences between 2D and 3D may be related to the fact that in 3D dendrimer NPs need to diffuse through the dense hydrogel mesh to target the encapsulated cells.

Together, these results indicate a targeted internalization of YIGSR-CMCht/PAMAM dendrimer NPs toward HCT-116 cells overexpressing $67 \mathrm{kDa}$ LR both in 2D and 3D. However, different levels of internalization levels were obtained when comparing both conditions, reinforcing that traditional 2D models may poorly correlate with human disease states.

\subsection{Targeted Gemcitabine Delivery Using Dendrimer Nanoparticles in 2D and 3D}

After verifying the targeted and preferential internalization of YIGSR-CMCht/PAMAM NPs toward HCT-116 cancer cells, we next investigated the gemcitabine (GEM) release from YIGSR-
CMCht/PAMAM in a co-culture of HCT-116 cancer cells and L929 fibroblasts in 2D and 3D. ${ }^{[21]}$ In a previous work, we demonstrated an encapsulation efficiency of GEM into CMCht/PAMAM NPs of $52.99 \% \pm 3.50 \%$, with a drug-loading efficiency of $9.42 \% \pm 3.50 \% .{ }^{[22]}$ First, the viability of cells was analyzed by live/dead assay in a 2D co-culture at $24 \mathrm{~h}$ and $72 \mathrm{~h}$ in the presence of GEM-YIGSR-CMCht/PAMAM (Figure 5A). The results show that L929 fibroblasts (in blue) were not substantially affected by the GEM-YIGSR-CMCht/PAMAM NPs; they were costained in blue and in green (live cells). In contrast, HCT-116 cancer cells (unstained) displayed a larger mortality at $24 \mathrm{~h}$ (reddead cells) (Figure 5A) indicating a specific GEM release inside these cells. It is worth noticing that most of the cancer cells were alive at $24 \mathrm{~h}$. However, they displayed an elongated-perturbedphenotype with the appearance of blebs, which suggested the beginning of the apoptotic process. ${ }^{[23]}$ In contrast, this was not observed in L929 cells. This was more stringent at $72 \mathrm{~h}$, where mainly HCT-116 cancer cells were dead. In contrast, L929 were mostly alive, displaying a morphology consistent with its normal phenotype and not significantly perturbed. We confirmed these 
qualitative observations by quantifying the amount of live/dead cells by flow cytometry. For this, CD44-FITC was used to label HCT-116 cancer cells, while L929 fibroblasts were CD44 negative and PI labeled the dead cells. Figure 5B shows a $4.70 \%$ of cell death (PI staining) in the CD44 positive population (HCT116 ) in $2 \mathrm{D}$ at $24 \mathrm{~h}$, and $3.44 \%$ for the CD44 negative population (L929). Although not very substantial at such early time point, there is a difference between both cell death values, being higher for cancer HCT-116 cells. The same trend was observed in 3D, where cell death for the CD44 positive (HCT-116) and negative (L929) populations was $30.16 \%$ and $26.07 \%$, respectively. Note that the percentage of overall cell death is higher in $3 \mathrm{D}$ than in 2D. This phenomenon could be related to the process of retrieving cells from the hydrogel. This process consists of leaving the hydrogels in the recovery solution at $4{ }^{\circ} \mathrm{C}$ for at least $30 \mathrm{~min}$. This may damage the cells, and therefore, may explain the increase in percentage of cell death.

At $72 \mathrm{~h}$, we observed a high level of internalization in HCT-116 cancer cells in 2D compared to L929 fibroblasts. This resulted in a significantly higher level of cell death $(68.72 \%)$ observed in the CD44 positive population (HCT-116) compared to L929 fibroblasts $(3.20 \%)$; this was in agreement with the previously studied internalization phenomena. In 3D, after exposing the co-culture to GEM-YIGSR-CMCht/PAMAM for $72 \mathrm{~h}$, cell death percentage of the CD44 positive population (HCT-116) was $31.15 \%$, while for the CD44 negative population (L929) was 19.52\%. These results show that the intracellular release of GEM was successfully achieved mainly toward cancer cells. However, when comparing the same condition at $24 \mathrm{~h}$, we observed that the level of cell death did not increase significantly. This could be explained by several possible factors: i) the GEM is released within the first $24 \mathrm{~h}$, being almost $40 \%$ released in the first 6 h of culture. ${ }^{[2]}$ Since a static culture is employed and fresh medium is not added, the drug levels are stable, therefore, cell death is also stable both at $24 \mathrm{~h}$ and $72 \mathrm{~h}$; ii) internalization rates do not drastically increase from $24 \mathrm{~h}$ to $72 \mathrm{~h}$ in 3D. This also corroborates the fact that there is no significant difference in the amount of drug available inside the cells to induce apoptosis from $24 \mathrm{~h}$ to $72 \mathrm{~h}$; and iii) at $72 \mathrm{~h}$, cells seem to be in the beginning of the process of apoptosis (Figure 5A), as suggested by the presence of both green and red signals. This also suggests that HCT-116 cancer cells may take longer time to complete the cell death process and to be detected by flow cytometry.

Taken together, these results suggest the successful targeting and release of the GEM-YIGSR-CMCht/PAMAM dendrimers NPs into the HCT-116 cells taking advantage of the $67 \mathrm{kDa}$ LR overexpression on the cell surface.

Finally, the rationale of using YIGSR (a peptide derived from laminin) as a tumor targeting is based on the solid evidences that the levels of expression of the $67 \mathrm{kDa}$ LR directly correlate with the invasiveness and metastatic potential in numerous tumors. ${ }^{[13,14,24]}$ It is our goal to further test these newly developed NPs using primary colorectal cancer cells and noncancerous colorectal cells in a dynamic microfluidic system, in order to better mimic the native scenario.

Overall, the future perspective of targeted NPs for cancer research is promising. Several formulations currently under preclinical and clinical studies for CRC may soon reach the market. A future challenge common to recent technologies, with no exception for targeted NPs, is the need for implementation of systems or protocols to determine the molecular expression profile of tumors from patients with CRC. Its classification according to the genetic profile, stage of tumor development, and putative targeting molecules is imperative. ${ }^{[25]}$ By achieving this, the rational administration of precise-targeted nanomedicines containing the most effective drug combination may revolutionize the way cancer is treated.

\section{Conclusion}

The conjugation of ligands, such as peptides, aptamers, and other small molecules (e.g., antibodies) on the surface of NPs for cell targeting has resulted in a new generation of NPs for cancer therapy with enhanced in vitro and in vivo specificity. This work demonstrates the development of YIGSR-CMCht/PAMAM dendrimer NPs. Its specificity toward the $67 \mathrm{kDa}$ receptor protein was first demonstrated in vitro by means of a micro-pattern assay. Next, we showed that YIGSR-CMCht/PAMAM dendrimer NPs preferentially targeted HCT-116 cancer in a co-culture with L929 fibroblasts, specifically releasing the anticancer drug intracellularly. These novel NPs demonstrated that they may be considered as a promising tool for targeted drug delivery in CRC and other cancer types with high levels of the 67LR. In the future, such technology will need to be evaluated in other CRC cell lines and primary cells to fully disclose the potential of YIGSR-targeted NPs in cancer therapeutics. Finally, the potential of YIGSR-CMCht/PAMAM NPs for further applications is immense. This tool may bring closer to a clinical and pharmaceutical translatable setting for continuing research.

\section{Experimental Section}

\subsection{Synthesis of the CMCht/PAMAM Dendrimer Nanoparticles}

Dendrimer NPs were fabricated as described elsewhere. ${ }^{[15]}$ Briefly, using a chemical modification route of chitin (Sigma, Germany), we synthesized CMCht with a degree of deacetylation of $80 \%$ and a degree of substitution of $47 \%$. CMCht/PAMAM dendrimer NPs were prepared in a step-wise manner as follows: first, the increase of the dendrimers' generation was carried out. An appropriate volume of PAMAM-CT (G 1.5) in methanol was transferred to a volumetric flask. The starting compound was re-dissolved in ultrapure water to give a final concentration of $10 \mathrm{mg} \cdot \mathrm{mL}^{-1}$. The $\mathrm{pH}$ was adjusted to 6.5 with dilute hydrochloric acid solution (Riedel de-Haen, Germany). 1-Ethyl-(3-dimethylaminopropyl) carbodiimide hydrochloride (EDC, Fluka, Portugal) was then added to the solution at a molar ratio sufficient to modify the carboxylate residue of the dendrimers. The solution was kept under agitation for $30 \mathrm{~min}$ at room temperature. Ethylenediamine (EDA, Sigma, Germany) was added to the solution at a molar ratio equal to that of EDC and left to react for $4 \mathrm{~h}$. After this period, the excess of EDC was removed by dialysis (cellulose tubing, benzoylated for separating compounds with a MW $\leq 1200$, Sigma, Germany). After preparing the PAMAM-amine terminated compound, an exhaustive alkylation of the primary amines (Michael addition) was performed. An appropriate volume of PAMAM-amine terminated was mixed with methanol (Sigma, Germany) and methyl methacrylate. CMCht/PAMAM dendrimer NPs were then precipitated after addition of an appropriate volume of a saturated $\mathrm{Na}_{2} \mathrm{CO}_{3}$ (Sigma, Germany) solution and cold acetone (Pronalab, Portugal). Precipitates were collected by filtration and dispersed in ultrapure water for dialysis over a period of $48 \mathrm{~h}$. Finally, CMCht/PAMAM dendrimer NPs were obtained by freezing the solution at $-80^{\circ} \mathrm{C}$ and freeze-dried (TelstarCryodos-80) for 7 days. 


\subsection{Peptide Attachment onto CMCht/PAMAM Dendrimer Nanoparticles}

The attachment of YIGSR peptide (Genscript Corp, Piscataway, NJ, USA) to the NPs was performed via carbodiimide chemistry to form an amide bond between the carboxyl groups on the NPs and the amine groups at the YICSR N-terminal end group. ${ }^{[26]}$ CMCht/PAMAM $1 \%$ was prepared in buffer 2-( $N$-morpholino)ethanesulfonic acid) (MES, Sigma Aldrich, Germany), and mixed with the appropriate amount of NHS-Sulfo, EDC, and a $10 \mathrm{mg} \mathrm{mL}^{-1}$ YIGSR peptide solution (dissolved in MES buffer). The solution was stirred for $24 \mathrm{~h}$ and the NPs were recovered by dialysis against ultrapure water for $48 \mathrm{~h}$ followed by freeze-drying process for 7 days.

\subsection{Labeling of CMCht/PAMAM Dendrimer Nanoparticles with FITC}

The conjugates of CMCht/PAMAM-FITC were obtained by covalently bonding the CMCht amine group and the isothyocianate group of FITC (10 $\mathrm{mg} \mathrm{mL}^{-1}$ ) (Sigma, Germany) in anhydrous dimethyl sulfoxide (DMSO, Norconcessus, Portugal) creating a thiourea bond. First, a $10 \mathrm{mg} \mathrm{mL}^{-1}$ CMCht/PAMAM dendrimer NPs solution was prepared in a carbonatebicarbonate coupled buffer at $\mathrm{pH}$ 9.2. Then, a solution of FITC/DMSO was added under agitation and kept in the dark at $4{ }^{\circ} \mathrm{C}$ for $8 \mathrm{~h}$. Next, the FITClabeled CMCht/PAMAM dendrimer NPs solution was dialyzed against ultrapure water for $24 \mathrm{~h}$ to remove unlinked FITC and filtered (pore size $<220 \mathrm{~nm}$ ) in sterile and dark conditions. The final product was obtained after freeze-drying.

\subsection{Gemcitabine Incorporation into CMCht/PAMAM Dendrimer Nanoparticles}

Gemcitabine (GEM) was encapsulated in the NPs by mixing an aqueous solution of YIGSR-CMCht/PAMAM dendrimer NPs with an aqueous GEM solution with a final concentration of $5 \times 10^{4} \mathrm{M}$. Saturated sodium carbonate solution $\left(\mathrm{Na}_{2} \mathrm{CO}_{3}\right)$ and acetone was then added to the mixture. The resulting precipitates were dialyzed against ultrapure water. GEM-loaded YIGSR-CMCht/PAMAM dendrimer NPs were obtained by freezing the final solution at $-80^{\circ} \mathrm{C}$ and freeze-drying the samples

\subsection{Characterization of the CMCht/PAMAM Dendrimer Nanoparticles}

\subsubsection{Protein Quantification}

The concentration of YICSR peptide grafted onto the dendrimer NPs was estimated by UV spectroscopy (between 200 and $275 \mathrm{~nm}$ ) and the Micro-BCA $(562 \mathrm{~nm})$ protein quantification assay using a microplate reader (BIO-TEK, EUA). Samples of CMCht/PAMAM and modified YIGSRCMCht/PAMAM dendrimer NPs were dissolved in ultrapure water at a final concentration of $1 \%$ and compared to standards for protein quantification in triplicates.

\subsubsection{Dynamic Light Scattering (DLS)}

Zeta potential and the size of the CMCht/PAMAM and YIGSRCMCht/PAMAM dendrimer NPs were measured in a particle size analyzer (Zetasizer Nano ZS, Malvern Instruments, UK). Particle size analyses were performed by DLS in phosphate buffered saline (PBS) at $\mathrm{pH}$ 7.4 with low concentration of NPs and using disposable sizing cuvettes.
Electrophoretic determinations of Zeta potential were investigated using the universal "dip" cell at pH 7.4 in PBS solution. Zeta potential was also investigated in water.

\subsubsection{Nuclear Magnetic Resonance Spectroscopy (NMR)}

The structure of CMCht/PAMAM and YIGSR-CMCht/PAMAM dendrimer NPs was determined by $\mathrm{H}^{1} \mathrm{NMR}$. Both types of NPs were dissolved in deuterated water $\left(D_{2} O\right)$. Then, the NMR spectra were obtained with a Mercury-400BB operating at a frequency of $399.9 \mathrm{MHz}$ at $50{ }^{\circ} \mathrm{C}$. The 1D $1 \mathrm{H}$ spectra were acquired using a $45^{\circ}$ pulse, a spectral width of $6.3 \mathrm{kHz}$, and an acquisition time of $2.001 \mathrm{~s}$.

\subsubsection{Scanning Transmission Electron Microscopy (STEM)}

Dendrimer NPs morphology was investigated by STEM (Philips CM-12, FEI, The Netherlands), equipped with a MEGA VIEW-II DOCU camera and Image Software Analyzer SIS NT DOCU. For this, the NPs were stained with $2 \%$ of phosphotungstic acid and placed on the copper grids for observation.

\subsubsection{Fourier Transform Infrared (FTIR)}

The dried dendrimer NPs, prior to and after YIGSR attachment, were mixed with $\mathrm{KBr}$ (sigma) and placed between two disks. Pressure was applied ( 4.5 metric tons, Carver Inc.) on the disk to form a pellet. The spectrum of the formed pellet was measured by FTIR spectroscopy (Exuinox 55, Bruker Optics Inc., USA) in the range of $400-3500 \mathrm{~cm}^{-1}$.

\subsubsection{Microcontact Printing}

Poly(dimethylsiloxane) (PDMS) (1:10 w/w, Sylgard 184; Dow Corning) stamps were replicated from an SU-8 mold (MicroChem) fabricated by UV-photolithography (MIDAS MDA-400MA). The PDMS stamp was rendered hydrophilic by plasma treatment to maximize $67 \mathrm{kDa}$ LR patterning. Glass coverslips were plasma-treated for $1 \mathrm{~min}$ and incubated for $1 \mathrm{~h}$ under anoxic conditions in anhydrous methanol solution of $5 \%$ (3-aminopropyl) triethoxysilane (APTES; Sigma Aldrich, Germany). Next, the samples were washed with methanol followed by ultrapure water. Then, APTES-functionalized coverslips were incubated for $30 \mathrm{~min}$ in a solution of $1 \%$ gluteraldehyde (Sigma Aldrich, Germany) in ultrapure water. The micropatterned PDMS stamp was incubated with $10 \mu \mathrm{g} \mathrm{mL} \mathrm{L}^{-1} \mathrm{LR}$ protein (Abcam, Portugal) solution for $2 \mathrm{~h}$ and the excess was removed by nitrogen drying. Immediately, the PDMS stamp containing the LR was placed in contact with the functionalized glass coverslip for $5 \mathrm{~min}$. After releasing the stamp, FITC-labeled YIGSR-CMCht/PAMAM dendrimer NPs were incubated overnight.

\subsection{In Vitro Cell Culture in 2D and 3D}

\subsubsection{Cell Culture}

Human HCT-116 colorectal cancer cells and L929 fibroblasts were obtained from the American Collection of Cell Cultures (ATCC, USA). Cells were grown in Dulbecco's Modified Eagle Medium (Sigma Aldrich, Germany) supplemented with $10 \%$ fetal bovine serum and $1 \%$ penicillin/streptomycin (Gibco, USA) at $37{ }^{\circ} \mathrm{C}$ and $5 \% \mathrm{CO}_{2}$. Subcultures of cells were performed when confluence reached values of $\approx 90 \%$. Then, cells were plated at an initial density of $1 \times 10^{4}$ cells per well in a 24 -well plate 
for metabolic activity and DNA quantification. Co-cultures were used for internalization studies ( $1 \times 10^{4}$ of each cell type in 24-well plates).

\subsubsection{Immunocytochemistry}

L929 were pre-stained in red with CellTracker CM Dil ( $1 \mu \mathrm{M})$ and seeded at an initial density of $1 \times 10^{4}$ cells per well in a 24-well plate. At days 1 and 3, HCT-116 cancer cells and L929 fibroblasts in co-culture were fixed with $4 \%$ formalin (Sigma Aldrich, Germany) for 10 min and washed with PBS. Cells were permeabilized with $0.1 \%$ Triton X-100 (Sigma Aldrich, Germany) in PBS for 5 min and blocked with 3\% BSA (Sigma Aldrich, Germany) in PBS for 30 min. Immunolabeling was performed using a rabbit antihuman monoclonal antibody against $67 \mathrm{kDa}$ LR (Abcam, 1:200) as primary antibody, prepared in PBS $1 \% \mathrm{BSA}$ and incubated overnight at $4{ }^{\circ} \mathrm{C}$ The samples were incubated for $1 \mathrm{~h}$ at RT with the respective secondary fluorochrome-conjugated antibodies, anti-rabbit/mouse IgG (Invitrogen, dilution 1:1000). Immunofluorescence was observed under transmitted fluorescence microscopy (Zeiss, Germany) (LR in green: ex/em 488/517; Cell Tracker CM Dil in red: ex/em 594/618).

\subsubsection{Metabolic Activity}

Alamar blue (AB) assay was performed according to supplier's instructions to assess the metabolic activity of cells. The effect of CMCht/PAMAM, YIGSR-CMCht/PAMAM, and GEM-YIGSR-CMCht/PAMAM dendrimer NPs was assessed in terms of metabolic activity in each cell type separately. After 24 and $72 \mathrm{~h}$ in culture, specific cell culture medium containing $20 \% \mathrm{v} / \mathrm{v} \mathrm{AB}$ was added to the different culture wells. The system was incubated for $4 \mathrm{~h}$ after which fluorescence was monitored at $590 \mathrm{~nm}$ emission wavelength (excitation wavelength $530 \mathrm{~nm}$ ), using a microplate reader (FL 600, Bio-Tek Instruments). After each AB determination, cells were rinsed with PBS and fresh culture medium was added to continue the culture. Medium with $20 \%$ v/v AB was used as a blank.

\subsubsection{DNA Quantification}

To assess the effect of CMCht/PAMAM, YIGSR-CMCht/PAMAM, and GEM-YICSR-CMCht/PAMAM dendrimer NPs on cancer cells and fibroblasts separately, the total amount of DNA was measured using the fluorimetric double-stranded DNA (dsDNA) quantification kit (Quant-iT PicoGreen dsDNA Assay Kit, Molecular Probes). The cells were washed with sterile PBS and lysed with $1 \mathrm{~mL}$ of ultrapure water in each well. The cellular suspensions were transferred into microtubes, incubated in a water bath at $37{ }^{\circ} \mathrm{C}$ for $1 \mathrm{~h}$, and stored at $-80^{\circ} \mathrm{C}$ for further analysis. DNA standards were prepared with concentrations varying between 0 and $2 \mu \mathrm{g}$ $\mathrm{mL}^{-1}$. Next, $28.7 \mu \mathrm{L}$ of sample (or DNA standard), $71.3 \mu \mathrm{L}$ of PicoGreen, and $100 \mu \mathrm{L}$ of TE buffer were mixed in each well of an opaque 96 -well plate (Alfagene, Portugal), according to the manufacturer's protocol. Next, after 10 min incubation at RT, fluorescence was measured using an excitation and emission wavelengths of 485 and $528 \mathrm{~nm}$, respectively. Sample DNA values were read off from DNA standard curve.

\subsubsection{Live/Dead Assay}

The cell viability was assessed by calcein-AM and propidium iodide (PI; Life Technologies, Carlsbad, CA, USA) staining. L929 fibroblasts were first stained with CellTracker Blue CMAC (Alfagene, Portugal), whereas HCT-116 cells were left unstained. After $72 \mathrm{~h}$, three samples were incubated in $1 \mu \mathrm{g} \cdot \mathrm{mL}^{-1}$ calcein-AM and $5 \mu \mathrm{g} \cdot \mathrm{mL}^{-1} \mathrm{PI}$ prepared in DMEM low glucose supplemented with sodium bicarbonate and $1 \% \mathrm{v} / \mathrm{v}$ antibiotic/antimycotic solution for $30 \mathrm{~min}$ in the dark at $37{ }^{\circ} \mathrm{C}$ in $5 \% \mathrm{CO}_{2}$. After PBS washing, samples were immediately analyzed in the confocal microscopy (Calcein-AM in green: ex/em 495/515 nm; PI in red: ex/em 495/635 nm; CellTracker Blue CMAC in blue: ex/em 353/466 nm) (Leica, SP8, Germany).

\subsubsection{Cellular Uptake}

HCT-116 colorectal cancer cells and L929 fibroblasts were pre-stained in Far Red and in Blue CMAC CellTracker (Alfagene, Portugal), respectively. After 30 min incubation at $37^{\circ} \mathrm{C}$, cells were seeded in co-culture at a density of $1 \times 10^{4}$ cells (each type)/well in 24-well plates, and allowed to adhere overnight. Then, the culture medium was replaced by fresh one supplemented with FITC-CMCht/PAMAM and FITC-YICSR-CMCht/PAMAM dendrimer NPs at a final concentration of $0.5 \mathrm{mg} \mathrm{mL}^{-1}$. At 24 and $72 \mathrm{~h}$, cells were washed with PBS, fixed with $4 \%$ formalin for 20 min at RT, washed three times with PBS, and permeabilized with $0.2 \%$ Triton X-100 in PBS for $10 \mathrm{~min}$. Next, cells were washed with PBS. The cell nuclei were stained with DAPI and F-actin with Phalloidin, as described above. The cells were imaged by confocal microscopy to assess the internalization of NPs (FITC $-488 \mathrm{~nm}$ ). For 3D studies, the same procedure was used. In this case, the cells were encapsulated into a $50 \mu \mathrm{L}$ Matrigel matrix (Enzifarma, Portugal).

\subsubsection{Flow Cytometry Analysis}

For internalization analysis, the cells were co-cultured in medium supplemented with $0.5 \mathrm{mg} \mathrm{mL}^{-1}$ of FITC-labeled YICSR-CMCht/PAMAM dendrimer NPs in 24-well plates $\left(1 \times 10^{4}\right.$ cells; each type/well). Cells cultured in complete culture medium were used as controls. After 24 and $72 \mathrm{~h}$, the cells were trypsinized (TrypleX, Life technologies, USA) and a cell strainer was used to avoid cell clusters. Next, $0.5 \mathrm{~mL}$ of DMEM complete medium was added to each well and the samples were transferred to flow cytometry tubes. To distinguish cells in co-culture, $10 \mu \mathrm{L}$ of PE-CD44 antibody (Abcam, Portugal) was incubated with HCT-116 cells for 20 min at RT. After washing with $2 \mathrm{~mL}$ of $2 \%$ FBS in PBS, the tubes were centrifuged at $300 \mathrm{rpm}$ for $5 \mathrm{~min}$ and re-suspended in 1\% formalin in PBS. The cell suspensions were analyzed in FACSCalibur flow cytometer (BD Biosciences, USA). A similar approach was followed for cell viability studies. In this case, the tubes were centrifuged at $300 \mathrm{rpm}$ for $5 \mathrm{~min}$ and HCT-116 were stained with FITC-CD44 (Abcam, Portugal) for $30 \mathrm{~min}$ and re-suspended in $2 \%$ FBS in PBS. Then, $1 \mu \mathrm{L}$ of PI was added to the cell suspensions and incubated for $10 \mathrm{~min}$ at RT, and analyzed by FACSCalibur flow cytometer. For internalization and cell viability assays in $3 \mathrm{D}$, cells encapsulated in Matrigel were retrieved using $500 \mu \mathrm{L}$ of Corning Cell Recovery Solution (Corning, USA) for $30 \mathrm{~min}$ at $4{ }^{\circ} \mathrm{C}$ and the subsequent protocol was performed as previously described.

For all assays, calibrate beads three-color kit (BD CaliBRITE beads, USA) was used to adjust the instrument settings before samples are run on the flow cytometer. Finally, data were analyzed using the Flowing Software 2 .

\subsubsection{Statistical Analysis}

Statistical analysis was performed using GraphPad Prism 5.0 software version 5.0a. The nonparametric Mann-Whitney test was used to compare two groups, whereas comparison between more than two groups was performed using the Kruskal-Wallis test followed by Dunn's comparison test. A value of $p<0.05$ was considered statistically significant.

\section{Acknowledgements}

This work was financially supported through the project FROnTHERA (NORTE-01-0145-FEDER-000023), Norte Portugal Regional Operational 
Programme (NORTE 2020), under the Portugal 2020 Partnership Agreement, through the European Regional Development Fund (ERDF); M.R.C. for her Ph.D. scholarship NORTE-08-5369-FSE-000044, funded by Programa Operacional Regional do Norte, Fundo Social Europeu, Norte 2020 TERM\&SC and EMBO Short-Term Fellowship 7232. J.M.O. for his distinction attributed under the FCT Investigator program (IF/00423/2012 and IF/01285/2015; F.R.M. acknowledges FCT for her work contract under the Transitional Rule DL 57/2016 (CTTI-57/18-I3BS(5)). D.C. acknowledges the financial support from the Portuguese Foundation for Science and Technology (FCT) under the program CEEC Individual 2017 (CEECIND/00352/2017). D.C. and S.C.K. for the Portuguese Foundation for Science and Technology (FCT) under the scope of the project 2MATCH (PTDC/BTMORG/28070/2017) funded by the Programa Operacional Regional do Norte supported by European Regional Development Funds (ERDF). This work is also partially supported by the IET Harvey Engineering Research Award 2018 (ENG ThE CANCER) and the European Union Framework Program for Research and Innovation Horizon 2020 on FoReCaST project under Grant Agreement No. 668983.

\section{Conflict of Interest}

The authors declare no conflict of interest.

\section{Keywords}

cancer cells targeting, colorectal cancer, dendrimers, nanoparticles, peptides

Received: July 5, 2019

Revised: August 20, 2019

Published online: xxxx 0, 2019

[1] R. L. Siegel, K. D. Miller, A. Jemal, CA Cancer J. Clin. 2018, 68, 7.

[2] H. Wu, H. Hu, J. Wan, Y. Li, Y. Wu, Y. Tang, C. Xiao, H. Xu, X. Yang, Z. Li, Chem. Eng. J. 2018, 349, 129.

[3] S. Senapati, A. K. Mahanta, S. Kumar, P. Maiti, Signal Transduct. Target. Ther. 2018, 3, 7.

[4] K. Sztandera, M. Gorzkiewicz, B. Klajnert-Maculewicz, Mol. Pharm. 2018, 16, 1. https://doi.org/10.1021/acs.molpharmaceut. 8 b00810.

[5] F. Alexis, E. Pridgen, L. K. Molnar, O. C. Farokhzad, Mol. Pharmaceutics 2008, 5, 505 .
[6] a) K. H. Bae, H. J. Chung, T. G. Park, Mol. Cells 2011, 31, 295; b) U. Kedar, P. Phutane, S. Shidhaye, V. Kadam, Nanomed. Nanotechnol. Biol. Med. 2010, 6, 714.

[7] L. P. Mendes, J. Pan, V. P. Torchilin, Molecules 2017, 22, 1401.

[8] B. Yu, H. C. Tai, W. Xue, L. J. Lee, R. J. Lee, Mol. Membr. Biol. 2010, 27, 286.

[9] E. Kopansky, Y. Shamay, A. David, J. Drug Targeting 2011, 19, 933.

[10] M. Sharma, R. Malik, A. Verma, P. Dwivedi, G. S. Banoth, N. Pandey, J. Sarkar, P. R. Mishra, A. K. Dwivedi, J. Biomed. Nanotechnol. 2013, 9, 96.

[11] G. Sarfati, T. Dvir, M. Elkabets, R. N. Apte, S. Cohen, Biomaterials 2011, 32, 152.

[12] M. Kumazoe, K. Sugihara, S. Tsukamoto, Y. Huang, Y. Tsurudome, T. Suzuki, Y. Suemasu, N. Ueda, S. Yamashita, Y. Kim, K. Yamada, H. Tachibana, J. Clin. Invest. 2013, 123, 787.

[13] A. Vacca, D. Ribatti, L. Roncali, M. Lospalluti, G. Serio, S. Carrel, F. Dammacco, Cancer 1993, 72, 455.

[14] Y. E. Shi, J. Torri, L. Yieh, M. E. Sobel, Y. Yamada, M. E. Lippman, R. B. Dickson, E. W. Thompson, Clin. Exp. Metastasis 1993, 11, 251.

[15] M. R. Carvalho, F. R. Maia, J. Silva-Correia, B. M. Costa, R. L. Reis, J. M. Oliveira, Nanomedicine 2017, 12, 581.

[16] S. R. Cerqueira, B. L. Silva, J. M. Oliveira, J. F. Mano, N. Sousa, A. J. Salgado, R. L. Reis, Macromol. Biosci. 2012, 12, 591.

[17] M. Valodkar, R. N. Jadeja, M. C. Thounaojam, R. V. Devkar, S. Thakore, Mater. Chem. Phys. 2011, 128, 83.

[18] J. M. Oliveira, N. Kotobuki, A. P. Marques, R. P. Pirraco, J. Benesch, M. Hirose, S. A. Costa, J. F. Mano, H. Ohgushi, R. L. Reis, Adv. Funct. Mater. 2008, 18, 1840.

[19] F. R. Maia, A. H. Lourenço, P. L. Granja, R. M. Gonçalves, C. C. Barrias, Macromol. Biosci. 2014, 14, 759.

[20] V. E. Rea, F. W. Rossi, A. De Paulis, P. Ragno, C. Selleri, N. Montuori, Infez. Med. 2012, 20, 8

[21] P. Jiménez-Fonseca, M. P. Solis, M. Garrido, L. Faez, D. Rodriguez, A. L. Ruiz, M. L. Sanchez Lorenzo, E. Uriol, M. D. Menendez, J. M. Viéitez, Clin. Transl. Oncol. 2015, 17, 384.

[22] M. R. Carvalho, D. Barata, L. M. Teixeira, S. Giselbrecht, R. L. Reis, J. M. Oliveira, R. Truckenmuller, P. Habibovic, Sci. Adv. 2019, 5, eaaw1317.

[23] E. Rudolf, M. Cervinka, Acta Med. 2005, 48, 29.

[24] E. Ardini, B. Sporchia, L. Pollegioni, M. Modugno, C. Ghirelli, F. Castiglioni, E. Tagliabue, S. Menard, Cancer Res. 2002, 62, 1321.

[25] B. A. Cisterna, N. Kamaly, W. I. Choi, A. Tavakkoli, O. C. Farokhzad, C. Vilos, Nanomedicine 2016, 11, 2443.

[26] F. R. Maia, K. B. Fonseca, G. Rodrigues, P. L. Granja, C. C. Barrias, Acta Biomater. 2014, 10, 3197. 